\title{
The patient said he would rather die: Should you let him?
}

\author{
Dov Fox, DPhil, JD, LLM, ${ }^{\mathrm{a}}$ Joseph S. Coselli, MD, ${ }^{\mathrm{b}}$ and Robert M. Sade, $\mathrm{MD}^{\mathrm{c}}$
}

\footnotetext{
From the ${ }^{\mathrm{a}}$ University of San Diego School of Law, San Diego, Calif; ${ }^{\mathrm{b}}$ Department of Surgery, Cardiothoracic Surgery, Baylor College of Medicine, and Texas Heart Institute, Houston, Tex; and ${ }^{\mathrm{c} D e p a r t m e n t ~ o f ~ S u r g e r y ~ a n d ~}$ Institute of Human Values in Health Care, Medical University of South Carolina, Charleston, SC.

Dr Sade's role in this publication was supported by the South Carolina Clinical and Translational Research Institute, Medical University of South Carolina's Clinical and Translational Science Award Number UL1TR001450. The contents are solely the responsibility of the authors and do not necessarily represent the official views of the National Center for Advancing Translational Science of the National Institutes of Health. Read at the 98th Annual Meeting of The American Association for Thoracic Surgery, San Diego, California, April 28-May 1, 2018.

Received for publication Aug 2, 2018; revisions received Aug 20, 2018; accepted for publication Aug 23, 2018; available ahead of print Sept 29, 2018.

Address for reprints: Robert M. Sade, MD, Medical University of South Carolina, 30 Courtenay Dr, Suite 277, MSC 295 Charleston, SC 29425-2270 (E-mail: sader@musc.edu).

J Thorac Cardiovasc Surg 2019;157:1092-6

$0022-5223 / \$ 36.00$

Copyright (C) 2018 by The American Association for Thoracic Surgery

https://doi.org/10.1016/j.jtcvs.2018.08.044
}

It is a well-established canon of law in the United States that every person has the right to determine what happens to his own body, including refusal of life-sustaining treatment. Surgeons often find it difficult to accept prima facie a patient's refusal of a lifesaving operation that the surgeon knows can be done with a reasonable degree of success. Fortunately, we do not face that problem very often, but when we do, we frequently struggle with how to handle the situation, because usually no simple answers are evident.

Just such a fictional case - a rupturing aortic aneurysmwas presented for debate at the 98th Annual Meeting of the American Association for Thoracic Surgery, pitting a professor of law with expertise in bioethics against a highly experienced cardiothoracic surgeon with a distinctly contrary view.

\section{THE CASE OF THE MAN WHO SAID "NO"}

James Lazarus is 78 years old and has had a recent onset of cough and hoarseness. Workup includes a chest film, which reveals a widened upper mediastinum, suspicious for aortic aneurysm. The computed tomography scan shows a 7-cm dilation of the aortic arch and upper descending aortic. He is referred to cardiothoracic surgeon Dr David Solomon, who recommends operative repair of the aneurysm. Although his wife of 60 years wants him to have the operation, Mr Lazarus declines, preferring to retain his cough and hoarseness to undergoing the risk of surgery. Dr Solomon records his recommendation and the patient's refusal in the patient's chart.

At follow-up visit in 6 months, repeat computed tomography scan shows expansion of the aneurysm to $8.5 \mathrm{~cm}$, and Dr Solomon strongly recommends operation, because dilation is advancing rapidly and rupture can occur at any time. If it ruptures, he will need an emergency operation with much higher risk than if it is done now, and without an operation he will

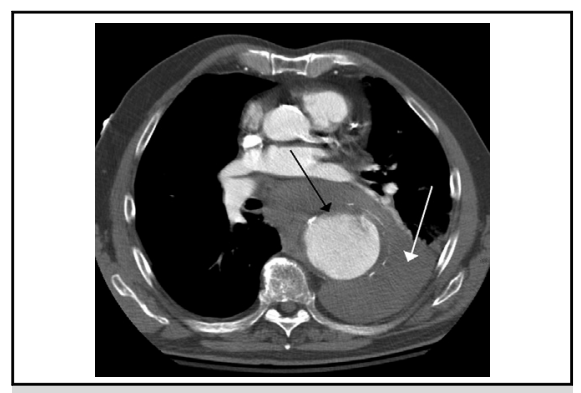

Computed tomography scan of ruptured thoracic aortic aneurysm. Aorta (black arrow) and blood in thorax (white arrow)

\section{Central Message}

Adult patients can refuse any medical intervention, even a lifesaving operation. A health care agent wants aortic rupture repaired, against the incapacitated patient's wishes. What should be done?

die. Mr Lazarus again refuses despite all efforts at persuasion by the surgeon and by his wife. He states that he simply does not want an operation. Dr Solomon records his recommendation and the patient's refusal in the patient's chart.

Two months later, Mr Lazarus develops sudden onset of severe back pain and syncope. By the time he arrives at the emergency department accompanied by his wife, his vital signs indicate hypovolemic shock. His aneurysm is clearly leaking. He is progressively more disoriented and confused.

As fluids and circulatory support drugs are being administered, Mrs Lazarus reminds Dr Solomon that she is her husband's health care agent under his health care durable power of attorney. She tells him to perform the operation as an emergency-her husband really does not want to die and will be happy to be alive when he wakes up in the intensive care unit. Dr Solomon is torn over the decision; should he accept the patient's refusal?

\section{PRO}

\section{Dov Fox, DPhil, JD, LLM}

Dr Solomon should accept the patient's refusal. The medical profession and legal culture prize the patient's right to self-determination and ability to make choices about his own treatment, even when refusal will likely result in death. The patient, Mr Lazarus, is not presently competent. But he had already made plain - on multiple occasions, while fully competent-his decision to forego the same lifesaving 
surgery under relevantly similar circumstances. So Dr Solomon should reject the request by Mr Lazarus's wife to perform the operation on her husband out of respect for the patient's contrary preference for death over surgery.

\section{The Patient's Refusal}

We do not learn of Mr Lazarus's reasons. He might have distrusted Western medicine. Maybe he did not want to lengthen a life of poor and worsening quality. Or perhaps he "feared the operation... might, at his age, leave him [so] mentally or physically crippled" that he would "rather die" than fall prey to the "major complications" that surviving patients endured. He would rather "[gamble] on long odds that his damaged aorta would heal on its own" and accordingly "ch[o]ose to receive care at home." ${ }^{1}$ Whatever his reasons, Mr Lazarus made his ultimate decision clear and convincing. Dr Solomon should therefore take no for an answer and respect his right to decline treatment.

Mr Lazarus validly expressed his informed refusal. Coughing and hoarseness certainly did not cloud his ability to understand information about his condition and its consequences, to reason and deliberate about his options, to make a choice consistent with his values and goals, and to communicate this choice to Dr Solomon-indeed, consistently over time. Dr Solomon had warned him that aortic aneurysm rupture carries a $90 \%$ mortality rate. And $\mathrm{Mr}$ Lazarus gave no indication that he failed to appreciate the meaning, imminence, and probability of death. Nor is there reason to think that he was missing some key insight or perspective from his medical team or family; at least his treating physician and wife were involved in his decisionmaking process from the outset. Mr Lazarus refused the surgery competently and voluntarily.

That he is presently disoriented and confused does not invalidate his earlier refusal. An incompetent patient retains his right to refuse even as he is unable to assert it. That respect for patient autonomy extends in incapacitation calls for determining what the patient would choose if he could. This "substituted judgment" standard privileges a patient's prior statements that indicate what he already decided about treatment in the circumstances that are now present. Other factors may also be relevant to consider in deciding whether to treat. These include family members' beliefs about a patient's values and personality, and the patient's current condition, treatment options, prognosis, and degree of suffering. But none-not a doctor's "best interest" judgment or a spouse's own anguish-should override a patient's clearly expressed wishes to the contrary. ${ }^{2}$

\section{Substituted Judgment}

Legal "authorities are in agreement that any surrogate, court appointed or otherwise, ought to be guided in his or her decisions first by his knowledge of the patient's own desires and feelings, to the extent that they were expressed before the patient became incompetent." ${ }^{3}$ And in the absence of such statements, judges "must probe the patient's value system as an aid in discerning what the patient would choose" with "special attention to the known values and goals of the incapacitated patient" to "extrapolate from those values and goals what the patient's decision would be." ${ }^{4}$ These principles should guide Dr Solomon's decision.

The substituted judgment standard has been criticized on the ground that many medical emergencies are unexpected, and it is often impossible to know for sure what a patient would have done had she or he been able to make an autonomous choice. Whatever their merit, these difficulties do not apply in the case of Mr Lazarus. On 2 separate occasions, 6 months apart, Dr Solomon specifically informed him of risks associated with his rapidly worsening aneurysm; he told Mr Lazarus that an emergency surgery with a less successful result would be required if his aneurysm ruptured, and he made sure that his patient knew that he would die without the operation. Both times, Mr Lazarus refused the surgery in no uncertain terms: "He simply does not want an operation."

"The decisions of surrogates should, when possible, attempt to replicate the ones that the patient would make if capable of doing so." ${ }^{, 5}$ Doctors should resort to a "best interest" standard in treating the incompetent patients only in the absence of evidence about their previously expressed wishes. ${ }^{6}$ Here, Mr Lazarus made his wishes clear and convincing from the start. And those wishes were reflected in Dr Solomon's written notes about his case. Repairing the aneurysm whether before or after the rupture requires a highly similar surgical procedure. And Dr Solomon had informed Mr Lazarus of the relevant likelihood (90\%) of the precise consequence (death). So the patient had already considered and repeatedly refused the very treatment being proposed. The specificity, consistency, proximity, and solemnity of his prior statements afford his prior refusals substantial probative value-enough to credit them as substituted judgment under "circumstances highly similar to the current situation." 7

\section{Legal Standards}

Courts have held that "when an individual has clearly and convincingly in advance of treatment expressed his decision, not to be maintained by life-sustaining procedures, ... health care professional[s] must respect that decision." ${ }^{8}$ Sure, Mr Lazarus might have been even more clear. $\mathrm{He}$ could have memorialized his refusal of lifesaving surgery even after his aneurysm were to rupture. Or he could have stated that he did not want any operations under any circumstances, even if death was otherwise certain. Short of these, however, he was about as explicit as he could have been, and certainly clear and convincing. Mr Lazarus was well within his right to refuse treatment and accept death. And that decision was altogether intelligible in light of his advanced 
age and low chances of survival. Indeed, many competent individuals opt to decline treatment that would in their view merely prolong their death rather than saving their life. $^{9}$

Mrs Lazarus demands the operation, stating her husband "really does not want to die and will be happy to be alive when he wakes up in the ICU." But her husband had unambiguously rejected that same operation even after having been warned of his certain demise without it. Her resolve to green-light the operation notwithstanding her husband's multiple prior refusals may be contaminated by her own fears, interests, and guilt, or what she believes to be in the best interest of her husband. Based on his own clear statements as recorded in his medical record, however, this does not seem like what her husband would have wanted if he were presently capable of making the decision himself.

She is in no better position to guess what he would have wanted. If she has new or more probative evidence from recent conversations or diary entries or otherwise, she should provide it. But otherwise, Dr Solomon should keep in mind that surrogates tend not to be very good at guessing whether or not patients themselves would have wanted to be treated. A representative study of 50 patients and their health care proxies found that "[s]urrogates correctly guessed patients' wishes about life support... no more accurate than random chance." The researchers concluded that in light of our results, the patient's own input into... decisions should be maximized whenever possible." ${ }^{10}$ Courts have accordingly warned against family members "relying on their own judgments or predilections rather than serving as conduits for expressing the patient's wishes." 11

No less than the US Supreme Court overruled a health care agent's decision to treat at a surrogate's insistence, explaining that "there is no automatic assurance that the view of close family members will necessarily be the same as the patient's would have been had she been confronted with her situation while competent." ${ }^{12}$ Dr Solomon should not follow the wife's decision just because she has been given authority to make medical decisions for him considering his incapacitated state. This is a hard case, to be sure. The doctor's decision will almost certainly leave Mr Lazarus dead. But the patient's prior wishes to refuse the surgery should be heeded. There is a reason why Dr Solomon's decision not to treat would avoid liability. It discharges the physician's duty to respect and honor his patient's autonomy.

\section{CON}

\section{Joseph Coselli, MD}

Dr Solomon should not accept the patient's refusal of the operation and should perform the operation as his wife requests. That Dr Solomon finds himself in a moral, ethical, and legal dilemma is easily understood. He is faced with apparently conflicting information regarding the treatment of Mr Lazarus. To evaluate the situation in which Dr Solomon finds himself, we are examining the facts as presented and avoiding speculation beyond the context of what is available.

It is reasonable to consider that Dr Solomon is struggling with what many medical ethicists consider "medical indications." Physicians do not make clinical judgments in a vacuum but base their decisions on an interpretation of facts and data regarding a patient's physical and psychologic condition. These are the foundations on which clinical judgments are made and used to achieve the goals of medical or surgical treatment for any given patient. These goals, by and large, include cure, compassionate care of illness, and prevention of further injury. ${ }^{13}$ In this particular case, the facts lead one to conclude that the patient is in a near-death clinical emergency. Science supports the conclusion that rupture of a thoracic aortic aneurysm, as in Mr Lazarus' case, results in the certain death of the patient if left untreated. $^{14}$

The situation in which Dr Solomon finds himself is an ethical tug-of-war between Mr Lazarus' verbally expressed medical desires and the judgment of an appropriately delegated surrogate acting on Mr Lazarus' behalf. To resolve this conflict, Dr Solomon must consider the principle of patient autonomy and Mr Lazarus' ability to contribute to the decision at hand. The principle of patient autonomy rests on "acknowledgment of the moral right of every competent individual to choose and follow his or her own plan of life and actions." 12 In following this principle, it is important to verify that the patient is mentally competent to make decisions and that evidence of decisional incapacity is lacking. ${ }^{15}$

At the time Mr Lazarus arrives at the emergency department, he is unable to contribute to the decision-making process for his treatment plan. For patients with this kind of decisional incapacity, written advance directives and other documentation can and should be used to determine the patient's wishes and should take precedence over verbally expressed directions. The importance of advance written directives is supported in the US Supreme Court case Cruzan v. Director, Missouri Department of Health, ${ }^{15}$ the decision from which states, "At common law and by statute in more States, the parol evidence prevents the variations of the terms of a written contract by oral testimony." Thus, written advance directives can supersede subsequent oral instructions. These documents allow patients to inform a physician of how they want to be treated at a future time when they might be unable to participate in decisions about their own care, providing clear and conclusive instructions that reduce room for uncertainty.

Three legally acceptable documents can convey the wishes of patients with regard to their medical care. The first is a Directive to Physicians, which is codified in the statutes of many states. The second is a formal living will. 
Our patient, Mr Lazarus, has neither of these. He has, however, appointed his wife as his agent under a durable medical power of attorney document - the third legally accepted advance directive. As the surrogate decision maker, his wife is in a position to exercise "substituted judgment" on behalf of the patient, her husband. Substituted judgment relies on the surrogate knowing the patient's preferences well enough to make decisions about the patient's medical treatment on the basis of those preferences. Whereas Mr Lazarus has expressed his wishes to Dr Solomon verbally, his spouse, Mrs Lazarus, has had far more opportunity to have heard the patient's expressed preferences, putting her in a superior position to infer the patient's preferences from her intimate knowledge of their life together.

As an example of a situation in which the patient's spouse acquired decision-making authority, we present the case of the renowned surgeon Michael E. DeBakey. ${ }^{1}$ In 2005, at the age of 97 years, Dr DeBakey presented to the Methodist Hospital in Houston, Texas, with an acute aortic dissection, self-diagnosed by DeBakey, who had pioneered surgical treatment for aortic aneurysm and dissection in the 1950s. Dr DeBakey first refused to be admitted to the hospital to treat his dissected aorta, despite knowing that without surgery, his condition would probably be fatal. Eventually, he was admitted, and his surgical partner, Dr George Noon, recommended surgery. Dr DeBakey agreed to reevaluate the situation at a later point; however, within a few days, the aneurysm expanded, and Dr DeBakey became unresponsive. Emergency operation became critical to saving Dr DeBakey's life.

Because of Dr DeBakey's advanced age, and believing that DeBakey had signed a document stating that he did not want surgery, the hospital anesthesiologists refused to anesthetize Dr DeBakey for the operation. The Methodist Hospital ethics committee convened in a late-night emergency meeting to determine whether the operation should proceed. During these deliberations, Dr DeBakey's wife, Katrin DeBakey, entered the room and demanded that the operation begin immediately. The ethics committee acquiesced, and the surgeons rushed to save Dr DeBakey's life. An anesthesiologist from the nearby Veterans Affairs hospital, Dr Salwa Shenaq, stepped in to anesthetize Dr DeBakey during the procedure. Dr DeBakey survived the operation and recovered well; while in recovery, he expressed to his doctors that he was glad that that they had decided to operate. DeBakey died 2 years later, at the age of 99 years, of natural causes.

Dr Shenaq later clarified that Dr DeBakey had actually not signed a document forbidding surgery. ${ }^{15}$ Without a written document available, substituted judgment by the spouse can again take precedence, although the presented case of Mr Lazarus is substantially more well defined and conclusive because the legal advance directive is available.
I believe our final resolution as to whether to proceed with surgery lies in the fact that the written legal document granting power of attorney trumps previous oral conversations that were not conducted during the emergency situation at hand. As stated in the Cruzan v. Missouri ruling, "We note that many courts which have adopted some sort of substituted judgment procedure in situations like this, whether they limit consideration of evidence to the prior expressed wishes of the incompetent individual, or whether they allow more general proof of what the individual's decision would have been, require a clear and convincing standard of proof for such evidence." 15 Here, the strongest standard of proof exists in the advance directive of the power of attorney; it would be legally disruptive if legal documents signed by competent adults were ignored. The patient has placed his trust in his wife and codified it legally. I believe our position has to be to honor her legal relationship and to trust, as Mr Lazarus did, that she has her husband's best interest at heart.

\section{CONCLUDING REMARKS \\ Robert M. Sade, MD}

Our 2 essayists hang their hats on different pieces of evidence relevant to what Dr Solomon should do. Fox points to written evidence of the patient's wish not to have the operation, namely, the surgeon's documentation in the medical record of Mr Lazarus's refusal of operation, which he expressed on at least 2 occasions. Although such documentation is not a first-person advance directive, it is a written record that carries evidentiary weight. He also points to the requirement for Mrs Lazarus to use substituted judgment - what her husband would have wanted done-rather than her own wishes, as the basis for her decision regarding whether or not to operate.

Coselli seems to have an advantage in citing a legally binding document: a durable power of attorney for health care in which Mr Lazarus appointed his wife as his health care agent, clear evidence that he trusted her to make decisions for him. Like the notes in the medical record, however, the health care agent's decision is not based on a first-person declaration by the patient. To solidify her position, Mrs Lazarus should have produced statements, made while her husband was competent, that he wanted the operation if and when his death became imminent. In the absence of such evidence, Mrs Lazarus might be making a judgment based on her own values rather than her husband's.

No matter what Dr Solomon decides, a final determination of what should have been done could be made in a court of law, but this would happen only if litigation resulted, an unlikely event in this scenario. Ultimately, the question of what the surgeon should do is not an issue of law-he faces the risk of litigation no matter what he does, from Mrs Lazarus if her husband dies without an operation and from Mr Lazarus if he lives. Rather, he has to decide what 
to do on ethical grounds. To make this ethical judgment, the surgeon should recognize that Mr Lazarus's authorization of his wife to act on his behalf as his health care agent presents a stronger prima facie case than comments recorded in the medical record. To overcome the presumption that Mrs Lazarus is acting on the basis of her husband's wishes, not her own, the surgeon must ask her to present oral or written comments the patient made stating that he changed his mind, specifically, that if his aorta ruptured, he wanted the operation rather than death. Our fictional vignette, The Case of the Man Who Said "No," unfortunately stops just short of providing the detail Dr Solomon would have needed to make a fully considered judgment of how he should proceed.

\section{Conflict of Interest Statement}

Authors have nothing to disclose with regard to commercial support.

D.F. thanks Lea Halvin and Savannah Montanez for excellent research assistance. R.M.S. thanks Professor of Law Nancy Zisk for advice and insights into legal and ethical implications of this debate.

\section{References}

1. Altman LK. The man on the table was 97, but he devised the surgery. New York Times. December 25, 2006. Available at: https://www.nytimes.com/2006/12/25/ health/25surgeon.html. Accessed August 6, 2018.

2. Lo B. Resolving Ethical Dilemmas: A Guide for Clinicians. 3rd ed. Philadelphia, PA: Lippincott Williams and Wilkins; 2005:86.

3. Barber v. Superior Court (1983) 147 Cal. App. 3d 1006, 1021.

4. In re A.C. (1990) 573 A.2d 1235 D.C.

5. President's Commission for the Study of Ethical Problems in Medicine and Biomedical and Behavioral Research. Deciding to forego life-sustaining treatment: a report on the ethical, medical, and legal issues in treatment decisions. March 21, 1983. Available at: https://repository.library.georgetown.edu/ bitstream/handle/10822/559344/deciding_to_forego_tx.pdf? sequence=1. Accessed August 6, 2018

6. In re Martin (1995) 450 Mich. 204, 228-229.

7. Conservatorship of Wendland (2001) 26 Cal. 4th 519, 541.

8. In re Gardner (1987) 534 A.2d 947, 953.

9. Garwinhas M. The duty to care-the right to refuse. J Legal Med. 2009;19: 99-125.

10. Suhl J. Myth of substituted judgment. Arch Intern Med. 1994;154:90-6.

11. In re A.C. (D.C. 1990) 573 A.2d 1235, 1238.

12. Cruzan v. Director, Missouri Department of Health (1990) 497 U.S. 261.

13. Beauchamp TL, Childress JF. Principles of Biomedical Ethics. 7th ed. New York: Oxford University Press; 2013.

14. Bickerstaff LK, Pairolero PC, Hollier LH, Melton LJ, Van Peenen HJ, Cherry KJ, et al. Thoracic aortic aneurysms: a population-based study. Surgery. 1982;92: 1103-8.

15. Shenaq S. DeBakey anesthesiologist fills in blanks. Newsl Am Soc Anesthesiol. 2007;71:45. 